\title{
Effect of Quality of Raw Materials on the Quality of Sponge Iron Manufactured in Laboratory
}

\author{
Dr. B.N.Roy \\ Asst Professor, Metallurgical Engineering Deptt. B.I.T.SIndri, Dhanbad, India-828123 \\ Rajni Kant Gaurav \\ M.Tech Student, Metallurgical Engineering Deptt. B.I.T.SIndri, Dhanbad, India-828123
}

\begin{abstract}
The physic-chemical principles of reduction of iron oxide in solid state are complex because although the reduction occurs that exact role played by the gaseous and solid reducing agents in the reduction of the iron oxide is uncertain. Much of the mechanism and kinetics of iron oxide reduction in the blast furnace stack hold true for direct reduction processes also. In fact the efficient nature of reduction of iron oxide in the blast furnace stack, where a gaseous and/or solid resultants reduce iron oxide in solid state led to the development of many a direct reduction processes carrying out only the role of blast furnace stack and remove partially reduced product without fusion.
\end{abstract}

Keywords: reduction, without fusion, solid reducing agents, unreduced iron oxide.

\section{INTRODUCTION}

Sponge Iron is a term given to the product that is obtained by reduction of iron oxide ore in solid state. Since separation of iron thus produced from the gangue oxide is not readily possible in solid state. Sponge iron is a mixture of reduced metallic iron unreduced iron oxide and the associated gangue constituents of the original ore. It is variously known as 'Sponge Iron', 'Direct reduced iron', 'Metallised ore' etc[1].

Directly reduced iron ore is neither iron nor ore as either ore normally considered. Much of oxygen associated with the iron oxide is eliminated, thereby raising the content of metallic iron. Oxygen in iron oxide is fairly big and hence its removal from the solid iron oxide lattice leaves the remaining mass, after the reduction, more porous and hence the term sponge iron. The term directly reduced iron originates from the fact that the iron oxide is directly reduced by the reluctant usually solid. The form metalized ore is derived from the fact that the metallic iron content goes up considerably in the process[2].

The percentage oxygen, associated with iron as oxide removed from the ore particle is often referred to as percentage reduction, where as the percentage of iron as part of the whole iron, existing as metallic iron is called degree of metallization in the sponge iron making technology[3].

When working of smaller units of direct reduction installations, cheaper reduction agents may be used for sponge iron production in the case of gas reduction processes one may fall back on natural gas available in large quantities from crude oil production processes one may use non-carbonizing[4]

Coal or lignite; both available almost in unlimited quantity.

A further process for steel production is the melting down of scrap. In developing countries, however scrap must usually be imported against payment of sear foreign currencies, so that in countries which have energy as well as ore available at reasonable prices the buildup of a national steel production on the basis of direct reduction is of high economic attraction [5]. But in highly developed industrialized countries there will undoubtedly be a demand for sponge iron too. As due to the expansion of the continuous casting process with its high yield, valuable scrap will become scares so that a shortage of scrap is anticipated for the 80 's. This shortage could be balanced by the sponge iron capacities to be newly created.

Because of the greater maneuverability in the selection of reduction installation and reduction agents, a lot of processes have been suggested. But the field of almost 40 known direct reduction processes has narrowed down considerably amongst the industrial processes we differentiate between retort processes; shaft furnace process, fluidized bed and rotary with process[6]. 
Under the retort process the ore is reduced discontinuously in a container by gas flowing through. In the shaft furnace process the lumpy ore is reduced by gas working in a counter current. In the fluidized bed process fine ore must be used which is held in suspension in a reduction gas stream with a sufficient high flow rate being reduced in the process [7]. The industrial development of direct reduction started towards the end of 1967 in Mexico, when the first HYL installation in Monterrey was started up by the Hojalatay Lamina USA. In the mean time this retort process holds the second largest share worldwide of all direct reduction process. At the beginning of the 60's the potential of direct reduction was thoroughly studied in Europe and in USA. Fundamental Research was carried out. The scientists believed the optimum principle of gas reduction could be implemented in a counter current shaft furnace. Development work in this field in Germany led to the Thyssen-Purofer process and the USA to the Midrex and Armco Process [8].

Amongst direct reduction processes utilizing solid reduction agents for sponge iron production, the rotary kiln process, the SL/RN process by Lurgi and the Codir process by Krupp all developed in Germany, are predominant throughout the world. In the meantime two installation have been built in Venezuela (HB and Fior Process) working with a fluidized bed. These installations, however, will only produce a sponge product with a low degree of reduction [9].

Throughout the world, the installed capacity of direct reduction equipment for the production of sponge iron is steadily increasing. Amongst projects under construction and in planning there are mainly gas reduction processes, particularly in those countries which have their own deposits of cheap gas[10].

An estimate of the known and intended capacity by the end of 1981 showed that approximately $91 \%$ will be gas reduction and 9\% solid fuel reduction. Amongst the gas reduction process sthe Midrex process of the Korf Group of companies and the Maxicon HYL process Take iron's share with approximately $43 \%$ and $30 \%$ respectively. Despite the steady development of sponge iron capacities. Some drawback must be noted, mainly for economic reasons. These materialized above all in industrial countries, where in times of steel recession[11]. The scrap price falls so considerably that even high grade sponge iron which after all produced at fixed costs; can no longer complete with scrap. The sponge iron capacity in countries with lower production costs, however, has not yet reached a size which would permit the export of major quantities after domestic demands have been met. That is one of the sponge iron works now under construction in onden which is supposed to supply the European Sector with the pure raw material used for high grade steel production after 1981.

But it must be considered that with the increasing use of raw materials, a recycling of companion elements like lead or zinc become increasingly interesting[12]. Consequently, some processes have been modified in such a manner that they may be used both for ore reduction and for the reprocessing of waste products. The rotary kiln process seems to be particularly suited for this purpose. For processing complex ores as for example titanium sands and vanadium bearing ores, installations have been in operation for some time now in New Zealand and South Africa [13]. The processing of work products e.g. purple ore and metallurgical dusts has been particularly reutilized by the Japanese. Almost every major steel group has carried out its own process research on the subject.

\section{METHODOLOGY}

To study the effect of coal quality (volatile matter and fixed carbon content) on the reduction kinetics, two sets of coal samples were selected. The first set of coal samples was of equal volatile matters but different fixed carbon content but different volatile matters. With these two sets of coal samples, reduction tests were conducted at $1000 \mathrm{oC}$ with a fixed coal size $(-2+1 \mathrm{~mm})$. The results obtained have been plotted in Figure $1 \& 2$ respectively.

From Figure 1. it is observed that with increase in volatile matt.er content of coal from $32.58 \%$ to $38.45 \%$ the average rate of reduction increases from 5.4 to $6.0 \% / \mathrm{min}$. as is evident also from Table -1 .

Actually volatile matter of coal mostly consists of hydrocarbons which are very reducing agents. Hence, increasing amount of volatile matter in the coal favours the reduction rate because the gas-solid reaction is taken than solidsolid reaction. Hence, with increase in volatile matter content of coal, the rate of reduction increases.

The effect of fixed carbon content of coal on the reduction kinetics is shown in figure -2 from this figure it is observed that with increasing amount of fixed carbon content of coal from 41.45 to $44.76 \%$ the average rate of reduction increases from 7.8 to 8.4 per cent $/ \mathrm{min}$. This is because of increasing amount of carbon gasification which provided more carbon monoxide for the reduction. 
COAL- 1

COAL SIZE : $-2+1 \mathrm{~mm}$

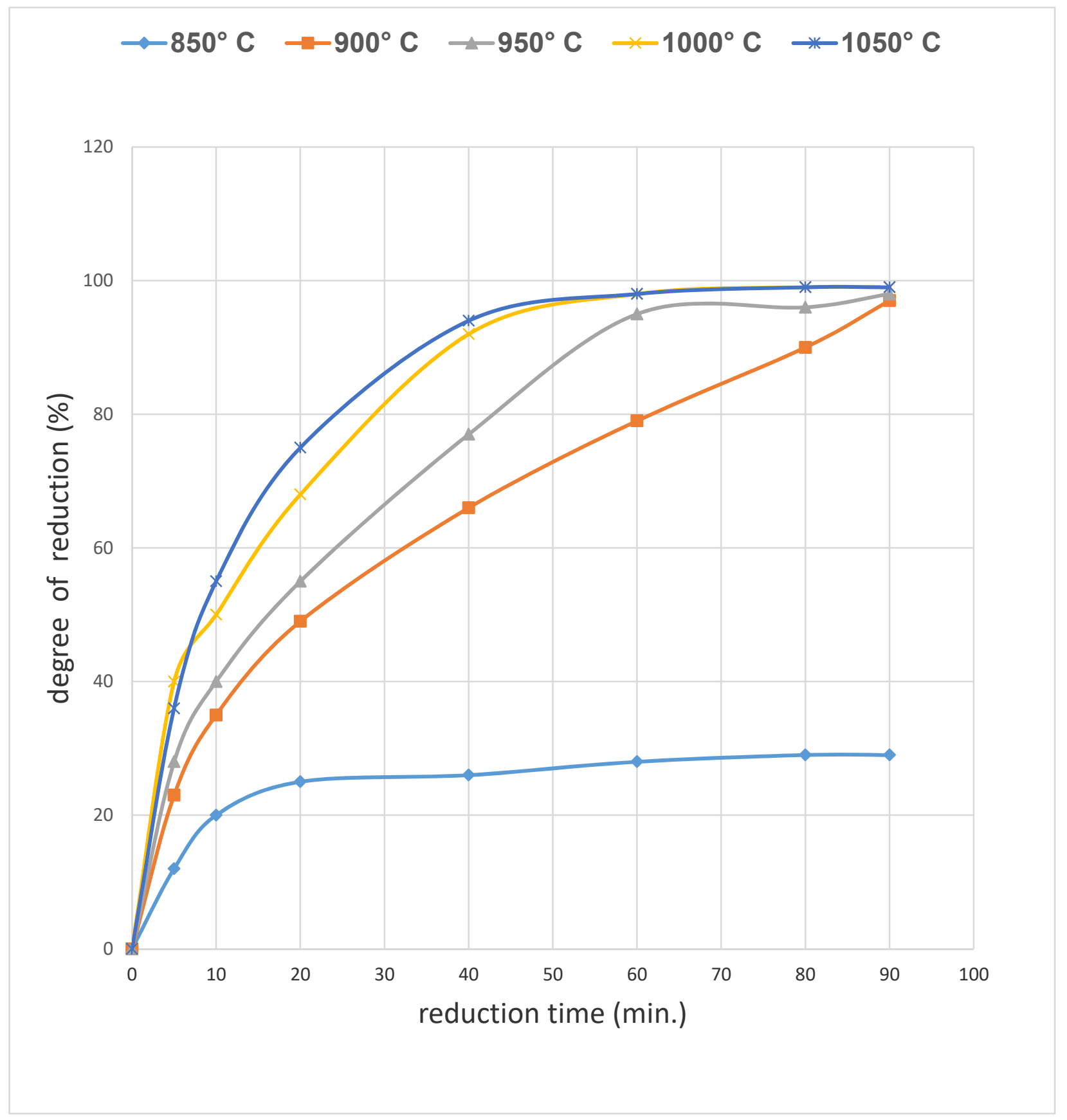

Figure 1. Effect of reduction time on degree of reduction at various temperatures. 
chemically pure iron oxide and non-coking coals from Raniganj Coalfield were taken for the present study. To compare the reduction behavior of pure iron oxide with natural iron ores, iron ores from Bailadila and Noamundi mines ere also taken. Charcoal was prepared in the laboratory for reduction tests. The chemical analysis of iron oxides and proximate analysis of non-coking coal have been shown in Table $-4 \& 5$ respectively.

Table - 4 - VARIABLE PARAMETERS AND THEIR RANGES

\begin{tabular}{|c|c|c|}
\hline Sl. & VARIABLES & RANGE \\
\hline 1 & Iron Oxide & $\begin{array}{c}\text { Pure iron oxide and natural iron oxide (Bailadila } \\
\text { and Noamundi) }\end{array}$ \\
\hline 2 & Shape & Pellets \& Lump \\
\hline 3 & Reductant & $\begin{array}{c}\text { Non coking coal } \\
\text { v.m. }=29.51 \% \text { to } 88.45 \% \\
\text { f.c. }=41.45 \text { to } 56.4 \% \\
\text { Ash }=12.0 \text { to } 23.4 \% \& \text { Charcoal }\end{array}$ \\
\hline 4 & Reduction Temperature & $850^{\circ} \mathrm{C}$ to $1050^{\circ} \mathrm{C}$ \\
\hline 5 & Reduction Time & 5 to 90 minutes \\
\hline 6 & Particle size of reductant & -3.32 to $0.152 \mathrm{~mm}$ \\
\hline
\end{tabular}

Table -5 CHEMICAL ANALYSIS OF IRON OXIDES

\begin{tabular}{|c|c|c|c|c|c|}
\hline SI & Sample & $\mathbf{F e} \%$ & $\mathbf{S i O}_{\mathbf{2}} \%$ & $\mathbf{A l}_{\mathbf{2}} \mathbf{O}_{\mathbf{3}} \mathbf{\%}$ & Others \\
\hline 1 & Pure Iron Oxide & 69.08 & -- & -- & 1.314 \\
\hline 2 & Bailadila Iron Ore & 64.2 & 3.32 & -- & 0.32 \\
\hline 3 & Noamundi Iron Ore & 61.6 & 2.4 & 2.8 & 6.729 \\
\hline
\end{tabular}

\section{EXPERIMENTAL PROCEDURE}

The reduction tests were carried out in silicon carbide muffle furnace. The detailed specification of the furnace is as follows:

Maximum Temperature

Length of furnace $=1450^{\circ} \mathrm{C}$

$=\quad 36.5 \mathrm{~cm}$ 


$\begin{array}{lll}\text { Width of furnace } & = & 16.0 \mathrm{~cm} \\ \text { Depth of furnace } & = & 14.0 \mathrm{~cm} \\ \text { Total volume of furnace } & = & 8176^{3} \mathrm{~cm} \text { or cu.cm } \\ \text { Current (Ampere) } & = & 0-30 \\ \text { Voltage } & = & 220 / 230\end{array}$

Reduction tests of iron oxide pellets and lump ores carried out by non-coking coal and charcoal under isothermal conditions.

To study the reduction behavior of pure iron oxide pellets at different temperatures, seven fired pellets having almost equal weight $(2 \mathrm{gm})$ were taken. Seven quartz crucibles were taken and one third portion of each crucible filled up by coal. The rest vacant space of the crucible was filled up by the same coal. Then they were put into the constant temperature zone of the furnace at the working temperature. Crucible were taken out one by one after 5 , $10,20,40,60,70$, or 75 and 80 or 90 minutes. The weight losses of all these pellets after reduction were found out and the degree of reduction of each pellet was calculated by using the formulae as below:

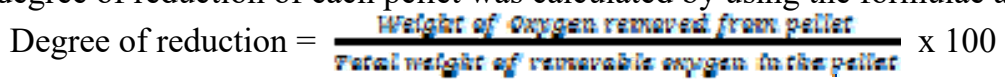

Weight of removed oxygen from the pellet was calculated directly from the weight loss of the reduced pellet. The carbon pick up by each pellet during reduction was not considered for calculating the degree of reduction. Before taking weight, the surface of the reduced pellets were deemed by hard to remove the coal particles stuck on the surface. Proper care were taken before taking the weight pellet was left in the crucible. The effect of all parameters mentioned in Table No.-04 was studied in the same way. At a time only one parameter was varied and rest were kept constant.

\section{RESULT \& DISCUSSION:}




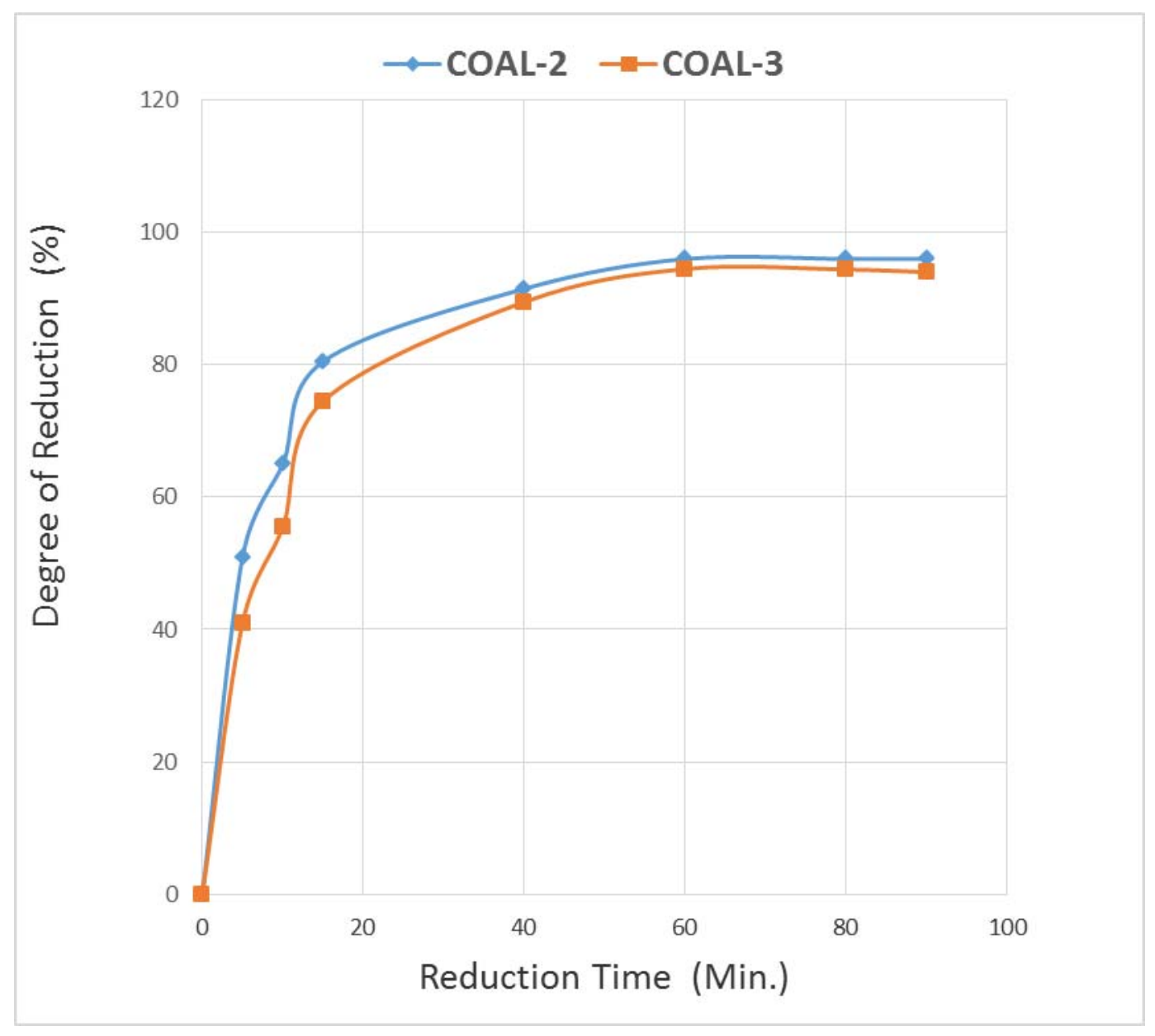

Figure 2. Effect of Volatile Matter contents of Coal on Pure Iron Oxide reduction

COAL SIZE : $-2+1 \mathrm{~mm}$

REDUCTION TEMP. : $1000^{\circ} \mathrm{C}$ 


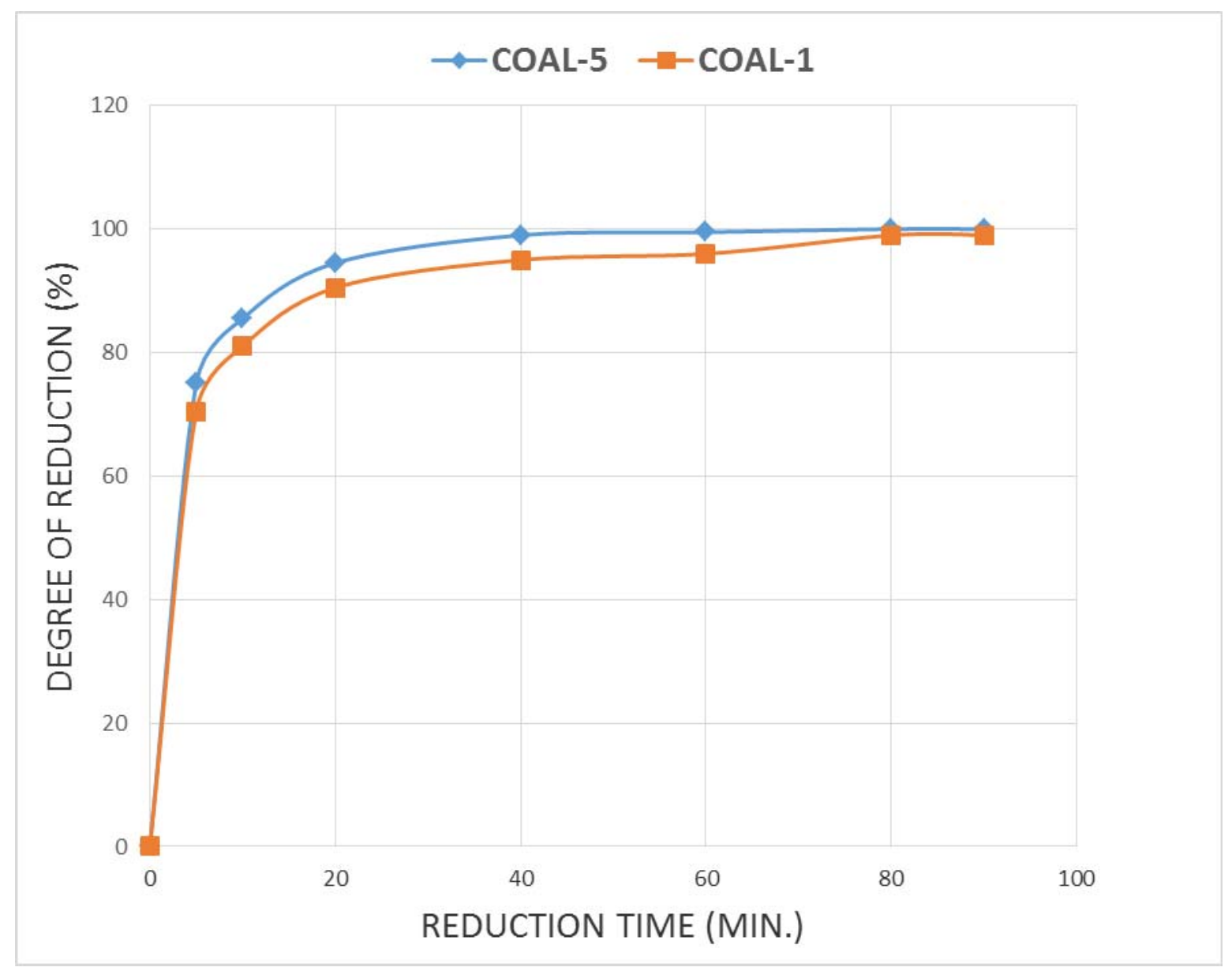

Figure 3. Effect of fixed Carbon content of Coal on Pure Iron Oxide reduction.

\section{V.CONCLUSIONS}

Based on the result and findings of this research work the following conclusions can be drawn:

$>$ The reduction rate is highly dependent on the coal quality (volatile matter and fixed carbon content). A coal with higher volatile matter and fixed carbon contents reduces iron at a faster rate.

$>$ With decreases in the particle size of coal the average rate of reduction increases.

$>$ The average rate of reduction increases with increases in reduction temperature.

$>$ All the reactions in the temperature range of $850 \mathrm{o} C$ to $1000 \mathrm{o} \mathrm{C}$ are coupled and the reactions are controlled by carbon gasification rate.

$>$ The initial rate of reduction of iron oxides with non-coking coals is higher than charcoal but the overall rate of reduction is higher in case of charcoal.

$>$ The average rate of reduction of pure iron oxide pellets is higher than the natural iron ore pellets and the rate of reduction of lumps ores is much slower than the pellets.

\section{REFERENCES}

[1] Gupta, S. K : Paper presented at the $3^{\text {rd }}$ Indo-Soviet Bilateral Symposium, R \& D Center, SAIL, Ranchi. Nov.1984.

[2] Reichelt, W : Metallurgical Plant and Technology, 4 (1985), 12.

[3] Ottmar, H. ,Schenck, H. and Dahi, W : Stahl U. Eisen 19, 15 (1979),731.

[4] Ganguly, Amit and Ditshit, S.K : Proc. Conf. on Alternative Iron making in Developing Countries, SEAISI, Bangkok, Sep. 1982.

[5] Dixon, J. M : IAMI,10 (1980), 6. 
[6] Direct from Midrex, 10 (4), (1985), 8.

[7] Direct from Midrex, 10 (3), (1985), 10.

[8] Chatterjee, Amit : Paper presented at the International Conf. on Alternative Routes to Iron and Steel Under Indian conditions, Jamshedpur, Feb. 1988.

[9] Feasibilty Report on Sponge Iron for Steel Authority of India Ltd., M. N. Dastur and Co. (P) Ltd., April 1975.

[10] Application of Latin American Oxide Raw Materials to the Midrex Direct Reduction Process by W. A. Ahrendt, Midrex Corporation.

[11] Iron bearing raw materials for Direct Reduction by Luther G. Hendrickson and Jesus A. Sandoval, Direct Reduction Iron- Technology and Economics of Production and Use, Published by ATME.

[12] Rao, Y. K : Metall. Trans., (1971), 1439.

[13] Baldwin, B. B. G : J. Iron \& Steel Inst. 179 (1955) 30. 